\title{
Visión panorámica del turismo mundial y la posición de Hong Kong en éste
}

$\mathrm{H}$ ong Kong es uno de los más importantes puntos de captación turística del mundo. $\mathrm{Su}$ reducido espacio y la consecuente escasez de recursos naturales no le ha impedido explotar ese sector estratégico para el desarrollo de su economía.

En este artículo analizo el peso relativo que tiene Honk Kong en los flujos y gastos turísticos a nivel mundial y las implicaciones para México.

\section{El turismo mundial}

A partir de la Segunda Guerra Mundial la actividad turística empezó a adquirir importancia en todo el mundo. El turismo fue visto cada vez más como un sector económico de grandes posibilidades, tanto por su capacidad de impulsar en cada país una mayor relación con el resto del mundo, como por su potencial para generar divisas, crear empleos e influir en el desarrollo de las regiones rezagadas.

En el contexto internacional se dio prioridad al turismo de masas ${ }^{1}$, centrado esencialmente en los atractivos que brindaban las playas. Para 1950 la Organización Mundial del Turismo (OMT) registró, alrededor del mundo, 25 millones de llegadas (es decir que visitaron determinados países) de turistas internacionales. Poco a poco la cifra de viajeros creció como consecuencia de la revolución

* Licenciada en estudios internacionales, $\mathrm{U}$ de $\mathrm{G}$. ORCID http://orcid.org/0000-0002-4553-8141 tecnológica e informática, que provocó, por un lado, el incremento en la velocidad y la evolución del transporte y, por el otro, impulsar a las compañías multinacionales y a una mayor interdependencia económica. Esto influyó positivamente para que las personas que por motivos de descanso, negocios, investigación, estudio, entre otros, se trasladaran a otros países, dando inicio con ello al desarrollo de la industria turística ${ }^{2}$.

Cincuenta años después (año 2000) el arribo de visitantes a escala mundial fue de 697 millones, es decir, manifestó un crecimiento de 2,616 por ciento, con relación a la afluencia turística de principio de los años cincuenta, lo que se traduce en un crecimiento promedio anual de 13.7 millones de llegadas de turistas internacionales durante el transcurso de esos cincuenta años ${ }^{3}$.

A principios de siglo XXI el ingreso económico derivado del turismo internacional fue de 474,000 millones de dólares. De éstos, aproximadamente la mitad los obtuvo Europa, le siguieron América, la región de Asia oriental y el Pacífico (cuadro 1).

Como se puede apreciar en el cuadro 1, del total de afluencia turística mundial, Europa recibe el mayor número de visitantes extranjeros, con 58 por ciento. Le sigue el Continente Americano con 18.5 por ciento y Asia oriental junto con el Pacífico suman 15.6 por ciento. Esta última región fue la que registró mayor crecimiento en el periodo de 1990 
Cuadro 1

Llegadas de turistas internacionales por regiones: $\mathbf{2 0 0 0}$

\begin{tabular}{lccc}
\hline & \multicolumn{3}{c}{ Variación (\%) } \\
& millones & $1999 / 2000$ & $1990-2000$ \\
\hline Mundo & 696.7 & 6.8 & 4.3 \\
Europa & 402.7 & 5.8 & 3.6 \\
América & 128.4 & 5 & 3.3 \\
Asia oriental y & 109.1 & 12.7 & 7.2 \\
África & 27.2 & 3.4 & 6.1 \\
Oriente medio & 23.2 & 13.2 & 10 \\
Asia meridional & 6.1 & 5.4 & 6.8 \\
\hline
\end{tabular}

Fuente: Organización Mundial del Turismo (www.world-tourism.org) domestica a través de la derrama económica (ingresos de divisas al país) y el dinamismo económico y social, además de los empleos que el sector genera. Al respecto la OMT publica anual-mente una lista de los principales países que se benefician de este sector (ver cuadro 2). Los países más visitados en el año 2000, y que pertenecen a la región de Asia oriental y el Pacífico, son China, Rusia y Hong Kong.

Como se muestra en el cuadro 2, al relacionar la dualidad de las llegadas y los ingresos por turismo, se observa que la afluencia turística no está directamente relacionada con los ingresos, ya que existen factores domésticos que abaratan o encarecen el gasto promedio del visitante: el tipo de cambio, la infraestructura turística y la calidad de los servicios ofrecidos por el país huésped, entre otros. Ejemplos claros son Rusia, Polonia y Hungría, los cuales aparecen dentro de los 15 países más visitados en el 2000; sin embargo, no figuran dentro de las economías que reciben los mayores ingresos por turismo, y viceversa, Australia, Turquía y Suiza no se incluyen en los países con mayor interés de los turistas a desplazarse hacia destinos turísticos poco explorados donde la cultura, la religión, la historia, las bellezas naturales y el movimiento económico son los principales puntos de atracción ${ }^{4}$.

Existen países en los que sin duda la actividad turística contribuye fuertemente en la economía
Cuadro 2

\begin{tabular}{|c|c|c|c|}
\hline Principales d & $\begin{array}{l}\text { stinos turísticos: } \\
2000\end{array}$ & $\begin{array}{r}\text { dro } 2 \\
\text { Principales rec } \\
\text { tur } \\
\end{array}$ & $\begin{array}{l}\text { eptores de ingresos por } \\
\text { ismo: } 2000\end{array}$ \\
\hline Países & $\begin{array}{c}\text { llegadas de turistas } \\
\text { internacionales } \\
\text { (millones) }\end{array}$ & Países & $\begin{array}{l}\text { Ingreso por turismo } \\
\text { internacional (miles de } \\
\text { millones de dólares) }\end{array}$ \\
\hline Francia & 75.6 & Estados Unidos & 82.0 \\
\hline Estados Unidos & 50.9 & España & 31.5 \\
\hline España & 47.9 & Francia & 30.7 \\
\hline Italia & 41.2 & Italia & 27.5 \\
\hline China & 25.2 & Reino Unido & 19.5 \\
\hline Reino Unido & 25.2 & Alemania & 17.9 \\
\hline Rusia & 21.2 & China & 16.2 \\
\hline México & 20.6 & Canadá & 10.7 \\
\hline Canadá & 19.7 & Austria & 10.0 \\
\hline Alemania & 19.0 & Grecia & 9.2 \\
\hline Austria & 18.0 & México & 8.3 \\
\hline Polonia & 17.4 & Australia & 8.0 \\
\hline Hungría & 15.6 & Hong Kong & 7.9 \\
\hline Hong Kong & 13.1 & Turquía & 7.6 \\
\hline Grecia & 13.1 & Suiza & 7.5 \\
\hline
\end{tabular}


Visión panorámica del turismo mundial y la posición de Hong Kong en éste

cuadro 3

Visitantes que arribaron a Honq Konq. países v reqiones (1996-2000) en miles

\begin{tabular}{rcccccccccc}
\hline Años & China & Taiwan & $\begin{array}{c}\text { Sureste } \\
\text { de Asia }\end{array}$ & Japón & Europa & $\begin{array}{c}\text { Estados } \\
\text { Unidos }\end{array}$ & $\begin{array}{c}\text { Australia y } \\
\text { Nueva Zelanda }\end{array}$ & Canadá & Otros & Total \\
\hline 1996 & 2,389 & 2,024 & 1,641 & 2,758 & 1,351 & 833 & 411 & 186 & 1,381 & 12,974 \\
1997 & 2,364 & 1,920 & 1,459 & 1,624 & 1,170 & 861 & 374 & 192 & 1,309 & 11,273 \\
1998 & 2,672 & 1,886 & 1,106 & 1,101 & 1,013 & 828 & 352 & 208 & 994 & 10,160 \\
1999 & 3,206 & 2,063 & 1,339 & 1,174 & 1,021 & 859 & 356 & 226 & 1,084 & 11,328 \\
2000 & 3.786 & 2.386 & 1,539 & 1.382 & 1.069 & 966 & 411 & 253 & 1.267 & 13.059 \\
\hline
\end{tabular}

Fuente: Information Services Department, www.gov.hk

número de turistas, pero sí se encuentran entre los que reciben mayores beneficios de este sector.

Una de las economías que se ubica dentro de los dos grupos es Hong Kong, la cual, no obstante su reducido tamaño, ocupa una envidiable posición entre los países con mayores ingresos por turismo.

Hong Kong se encuentra situado en la costa sur de China, con un área geográfica de $1,087 \mathrm{~km}^{2}$, y está compuesto, además, por la península de Kowloon y más de 200 islas; con 6.7 millones de habitantes, 70 por ciento de la población económicamente activa (PEA) se encuentra laborando en el sector servicios y directamente en el subsector turismo. ${ }^{5}$

\section{El turismo en Hong Kong}

Hong Kong es una mezcla única de Oriente y Occidente; con raíces chinas y patrimonio colonial británico, un reencuentro de lo ultramoderno y de antiguas tradiciones, es el destino turístico más popular de Asia. La industria del turismo es una de las principales captadoras de divisas. En el año 2000, los 13.1 millones de turistas que arribaron a esta nación aportaron a la economía un total de 7,900 millones de dólares, cifra que representó 5 por ciento del producto interno bruto (PIB). Cada visitante gastó durante su estancia un promedio de 4,539 dólares de Hong Kong (HK\$). De esta cantidad poco más de la mitad fue gastada en compras diversas, ya que precisamente los centros comerciales son uno de los principales atractivos turísticos de Hong Kong.
En cuanto a la infraestructura turística, para el año 2000, Hong Kong contaba con 92 hoteles que ofrecían en total 36,438 habitaciones. La estancia promedio de los visitantes fue de 3 noches, lo que derivó en una tasa promedio de ocupación, durante ese año, de 83 por ciento.

Los principales visitantes (en el 2000) provinieron de China ( 29 por ciento), le siguen Taiwan (18 por ciento), el sureste asiático (12 por ciento), Japón (11 por ciento), la Unión Europea (8.2 por ciento) y Estados Unidos con 7.4 por ciento. De hecho, debido a la gran afluencia turística que recibe la isla convirtió al aeropuerto internacional (Chek Lap Kok) en el de mayor tráfico en el mundo, al registrar vuelos de llegadas y salidas cada dos minutos durante las horas pico ${ }^{6}$.

Asimismo, en el año 2000, Hong Kong superó la cifra de turistas que alcanzó en 1997, año en que Hong Kong volvió a ser parte de la soberanía China bajo el funcionamiento de la fórmula "Un país, dos sistemas", hecho que coincidió con la crisis asiática. La incertidumbre política, social y económica de entonces repercutió hacia el exterior y provocó expectativas negativas que se reflejaron en la disminución de 13 por ciento en el número de visitantes a este destino. Después de este suceso, y debido a que el impacto transitorio fue menor a lo esperado mundialmente, la movilidad turística se reactivó, registrando un crecimiento promedio anual en la afluencia turística (19982000) de 9 por ciento ${ }^{7}$.

Debido a la transición política de Hong Kong, los visitantes apreciaron a un cambio evidente en la estructura del turismo: primero, 
aumentó el número de visitantes chinos debido a que se facilitó el ingreso de éstos al territorio de Hong Kong con fines turísticos, políticos o de negocio, pero no para los que buscan emigrar a la Región Administrativa Especial de Hong Kong (RAEHK). El aumento de los visitantes de China fue de 17 por ciento promedio anual. Por otra parte, disminuyó la afluencia de visitantes japoneses, europeos y de otros países, para volver a repuntar positivamente en el año 2000.

A partir de 1999, para hacer frente a la crisis asiática, el gobierno hongkonés tomó medidas económicas que le permitieran aumentar la competitividad. Una de ellas se centró en la actividad turística. $\mathrm{Al}$ respecto se adoptaron tres estrategias: a) desarrollar y mejorar la infraestructura turística, b) promover a Hong Kong como un atractivo destino turístico y c) mejorar la cordialidad turística de Hong Kong, tanto en la calidad de los servicios como de la industria misma. También en 1999 el Despacho de Servicios Económicos estableció la Comisión Turística, y la Oficina de Estrategias Turísticas (Hong Kong Tourism Board) con la función de asesorar al gobierno sobre asuntos y estrategias del turismo internacional.

El trabajo conjunto de estas dos organizaciones consiste en promocionar internacionalmente a Hong Kong como destino turístico; internamente tienen la función de mejorar y desarrollar la industria turística. El resultado de este esfuerzo fue evidente cuando se registró 15 por ciento de incremento en el número de visitantes que fue de 1999 al 2000.

Con excepción de los turistas asiáticos (de China, Taiwan y Japón), son los estadounidenses (como país, no región) los principales visitantes de esta economía, por lo que resulta interesante conocer los datos estadísticos sobre las preferencias de estos turistas por los países que visitan ya que según la OMT Estados Unidos, en el 2000, se colocó como el país con mayor gasto por turismo $(64,500$ millones).

Según datos de la Office of Travel \& Tourism Industries de los Estados Unidos, 31 por ciento de sus habitantes que viajó al exterior en el 2000 se dirigió a México, le siguieron Canadá, con 25 por ciento, y cuatro países de
Europa (Reino Unido, Francia, Alemania e Italia); Hong Kong fue el número catorce en las preferencias de los estadounidenses.

Un análisis regional sobre de los principales países de Asia-Pacífico con mayor preferencia por los turistas estadounidenses arrojaría que México, Canadá, Japón y Hong Kong ocuparon los primeros lugares, lo que confirma que éste es uno de los principales destinos turísticos para los viajeros del país que mayormente gasta en turismo (cuadro 4).

Como se puede observar en éste, la variación existente entre 1999 y 2000 de los viajeros estadounidenses a Hong Kong tuvo un aumento de 6 por ciento (idéntico al registrado por México, aun cuando la cercanía geográfíca resulta una ventaja para éste, y es superior al de Japón y Canadá), lo que representa un dato favorable; independientemente de que las cifras no fueron las más altas de los flujos turísticos presentados en el cuadro, éstas no se mantuvieron estancadas como en el caso de Canadá, ni decreció como fue el caso de Perú.

Reconociendo el gobierno hongkonés la efectividad de la industria turística y los beneficios económicos y sociales que se derivan de éste, además de las grandes oportunidades y amenazas que se presentan dentro de la región del Pacífico, se establecieron, a través del Hong Kong Tourism Board (HKTB), una serie de proyectos y estrategias para impulsar, mejorar

Cuadro 4

Principales países de la Cuenca del Pacífico más visitados por viajeros estadounidenses

\begin{tabular}{|c|c|c|c|}
\hline Economías & $\begin{array}{c}\text { Viajeros } \\
\text { (miles) } \\
2000\end{array}$ & $\begin{array}{l}\text { variación } \\
2000 / 1999\end{array}$ & $\begin{array}{c}\text { Viajeros } \\
\text { (miles) } \\
1999\end{array}$ \\
\hline México & 18,849 & $6 \%$ & 17,743 \\
\hline Canadá & 15,114 & $0 \%$ & 15,180 \\
\hline Japón & 1,262 & $1 \%$ & 1,254 \\
\hline Hong Kong & 832 & $6 \%$ & 787 \\
\hline Corea & 779 & $13 \%$ & 688 \\
\hline Australia & 698 & $18 \%$ & 590 \\
\hline Taiwan & 671 & $14 \%$ & 590 \\
\hline China & 644 & $14 \%$ & 565 \\
\hline Filipinas & 457 & $43 \%$ & 320 \\
\hline Nueva Zelanda & 457 & $24 \%$ & 369 \\
\hline Singapur & 457 & $9 \%$ & 418 \\
\hline Tailandia & 376 & $2 \%$ & 369 \\
\hline Perú & 322 & $-6 \%$ & 344 \\
\hline
\end{tabular}

Fuente: Office of Travel \& Tourism Industries U.S. (http:/tinet.ita.doc.gov/about/index.html). 
y desarrollar la actividad turística: 1) la construcción del Hong Kong Disneyland, con el cual se prevé que en un año completo de operación este centro de diversión traiga 5 millones de visitantes, incluyendo 1.4 millones de nuevos turistas y un ingreso económico de 1.100 millones de dólares; 2 ) la creación de un teleférico (Scenic Cable Car) que conectará Tung Chung con el nuevo aeropuerto de Chek Lap Kok y con Ngong Ping sobre la isla de Lantau, cerca del buda de bronce más grande del mundo; 3) la construcción del Hong Kong Wetland Park que tendrá como objetivo central sacar provecho de las riquezas naturales de la nación y que se le reconozca internacionalmente como área de reserva natural; 4) la creación de un centro de servicios de información internacional, mejor conocido como Cyberport, y 5) la remodelación del Ocean Park, entre otros. ${ }^{8}$

Por otro lado, el gobierno de Hong Kong ha puesto en marcha programas de apoyo y promoción al turismo con desarrollo sustentable ${ }^{9}$; para ello se intercambian experiencias y conocimientos con organismos internacionales como la OMT y APEC. Al respecto, este organismo, a partir de este año (2002), se ha fijado cuatro metas en este sector: 1) quitar los impedimentos al turista que viaja por negocios e inversión; 2) incrementar la movilidad de visitantes y la demanda de bienes y servicios turísticos; 3) analizar las consecuencias y el impacto de turismo, e impulsar, entre los países miembros, su manejo sustentable, y 4) realizar el reconocimiento y el entendimiento del turismo como un vínculo para el desarrollo social y económico. Tras estos objetivos se prevé que Hong Kong, como economía miembro de APEC, sea de los más beneficiados.

\section{Conclusión}

Hong Kong es uno de los 15 países más visitados del mundo; el cambio político (regreso a la soberanía China), junto con la crisis asiática en 1997, disminuyeron relativamente la afluencia turística a esta nación, pero la efectiva reestructuración administrativa en su sector turístico no solamente restableció el número de visitantes sino que lo incrementó, lo que le permitió posicionarse mundialmente, en el año 2000 , como el décimotercero país con mayores ingresos por turismo.
Reconociendo el importante papel que representa el turismo como generador de ingresos, el gobierno hongkonés, en aras por mantener y mejorar su competitividad mundial, puso en marcha una serie de proyectos (el Hong Kong Disneyland, el teleférico que conectará distintos destinos turísticos, parques temáticos entre otros) que se prevé aumentarán los atractivos turísticos y atraerá a un mayor número de turistas internacionales.

\section{Notas}

1 Al turismo convencional se le identifica como irrespetuoso de la naturaleza y de la cultura de los pueblos anfitriones, por lo que ocasiona graves problemas de índole físicoambientales y socioculturales en los lugares y en las comunidades locales (Gómez, 2000:23)

2 Fossaert, 1994: 157-160.

3 www.world-tourism.org/junio2002/data

4 1998,Thompson, Grahame, Economic Dynamism in the Asia Pacific, Routledge, London and New York. www.worldtourism/regional/east,asianandpacif.

5 www.asiared.com y World Bank 2001.

6 www.discoverhongkong.com y www.asiared.com.

7 Connelly, 2000:257) y www.gov.hk/tc.

8 www.info.gov.hk/topic_f.htm y Connelly, 2000:271.

9 Actividades turísticas que favorecen la salud, el deporte, la naturaleza y la cultura de los pueblos anfitriones.

\section{Bibliografía}

Connelly, Marisela, 2000, Asia Pacífico 2000, El Colegio de México.

Cuevas, Ana, 2001, "Variables socioeconómicas de las economías de APEC," en México y la Cuenca del Pacífico, núm. 13, Guadalajara, Jalisco.

Fossaert, Robert, 1994; El mundo en el siglo XXI, Siglo XXI Editores, México.

Gómez, Salvador, 2000, Bahía de Banderas: tendencias turísticas y competitividad, Universidad de Guadalajara, México.

Thompson, Grahame, 1998, Grahame, Economic Dynamism in the Asia Pacific, Routledge, London and New York.

www.info.gov.hk/topic_f.htlm

www.gov.hk/tc

www.discoverhongkong.com

www.world-tourism.org

www.chamber.org.hk/hknewsletters

www.asiared.com

www.worldtourism/regional/east,asianandpacif

www.apec.org 